\title{
RATIONALE USE OF PLATELET TRANSFUSION IN DENGUE FEVER-EXPERIENCE FROM A TERTIARY CARE HOSPITAL
}

\author{
Govindaraj Thimmarayan', Venkatraman Janarthanam²
}

${ }^{1}$ Assistant Professor, Department of Pathology, Sri Venkateshwaraa Medical College and Research Centre, Puducherry. ${ }^{2}$ Assistant Professor, Department of Pathology, Mahatma Gandhi Medical College and Research Institute, Puducherry.

\begin{tabular}{l}
\hline ABSTRACT \\
BACKGROUND \\
Dengue infection is caused by an arthropod-borne virus and transmitted by the vector Aedes aegypti. Dengue fever and dengue \\
haemorrhagic fever have emerged as a global public health problem in recent decades. Dengue Viruses (DV) belong to Flaviviridae \\
family and it has four serotypes referred to as DV-1, DV-2, DV-3 and DV-4.
\end{tabular}

\section{MATERIALS AND METHODS}

The present Retrospective study was conducted in the blood bank of a Tertiary Care Hospital in Puducherry over the period of 3 years from January 2012 to December 2015. Only dengue seropositive cases (121 cases) who have been platelet transfused were included in the study. Non-dengue patients and dengue patients who are not transfused with platelets were not included in this study. Patients clinical data, platelet count and platelet transfusion given to them were analysed.

\section{RESULTS}

Majority of the platelet transfused cases were in the age group between 31 to 40 years followed by third and second decade. Among all cases of platelet transfusion, female population was found to outnumber male population. Considering the guidelines of platelet transfusion, 42 (39\%) patients with platelet count $>20,000 / \mathrm{cu}$. $\mathrm{mm}$ in absence of bleeding or sepsis received inappropriate transfusion.

\section{CONCLUSION}

As platelet products are cost effective, precious and time consuming for preparation, there is a need to implement best platelet transfusion practices especially in developing countries like India. Irrational use of platelets will put the patient at a huge risk. A regular transfusion related audit or forming a committee comprising clinicians and transfusion medicine specialists is the effective way of increasing the likelihood of improving transfusion practices.

\section{KEYWORDS}

Dengue Haemorrhagic Fever, Dengue Shock Syndrome, Platelet Count, Platelet Transfusion, Rationale Use, Thrombocytopenia.

HOW TO CITE THIS ARTICLE: Thimmarayan G, Janarthanam V. Rationale use of platelet transfusion in dengue fever-experience from a tertiary care hospital. J. Evolution Med. Dent. Sci. 2016;5(70):5054-5057, DOI: 10.14260/jemds/2016/1148

\begin{abstract}
INTRODUCTION
Dengue infection is caused by an arthropod borne virus and transmitted by the vector Aedes aegypti. Dengue Viruses (DV) belong to Flaviviridae family and there are four serotypes of the virus referred to as DV-1, DV-2, DV-3 and DV-4. DV is a positive-stranded encapsulated RNA virus and is composed of three structural protein genes, which encode the nucleocapsid or core (C) protein, a membrane-associated (M) protein, an enveloped (E) glycoprotein and seven nonstructural (NS) proteins. ${ }^{1}$ All forms of serotypes can cause the complete spectrum of disease from a subclinical asymptomatic disease to a mild self-limiting disease, the Dengue Fever (DF) and a severe life threatening, the Dengue Haemorrhagic Fever/Dengue Shock Syndrome (DHF/DSS). ${ }^{1}$ The first evidence of occurrence of DF in the country was reported during 1956 from Vellore District in Tamil Nadu. The first DHF outbreak occurred in Calcutta (West Bengal) in
\end{abstract}

Financial or Other, Competing Interest: None.

Submission 10-08-2016, Peer Review 23-08-2016,

Acceptance 25-08-2016, Published 30-08-2016.

Corresponding Author:

Dr. Govindaraj Thimmarayan,

\#13, $6^{\text {th }}$ Cross,

Dr. Radhakrishnan Nagar,

Moolakulam,

Puducherry-605010.

E-mail: drgovindaraj.1981@gmail.com

DOI: $10.14260 /$ jemds $/ 2016 / 1148$
1963 with $30 \%$ of cases showing haemorrhagic manifestations over the past two decades. There has been global increase in the frequency of DF, DHF, and its epidemics with a concomitant increase in disease incidence. Various factors responsible for the resurgence of dengue epidemic include unprecedented human population growth, unplanned and uncontrolled urbanisation, both water supply and waste mismanagement and increased distribution and densities of vector mosquitoes. ${ }^{1,2}$ Dengue fever and dengue haemorrhagic fever have emerged as a global public health issue in recent decades.

The South East Asian countries such as India, Indonesia, Myanmar and Thailand are at the highest risk of dengue accounting for nearly half of the global risk. ${ }^{2}$ The very first case of existence of dengue fever in India was way back in 1946 and gradually the whole country was involved with wide spread epidemics followed by endemic prevalence of all the four serotypes of Dengue virus. ${ }^{3}$ Since, there is reduced production and increased destruction of platelets by the action of virus, Thrombocytopenia is the universally observed feature in dengue infection. ${ }^{2}$ The role of platelet transfusion plays the major role in dengue infected patients especially in Dengue haemorrhagic fever where a standard clinical practice is adopted in many dengue endemic countries for the proper use of platelets. Platelet concentrates due to their shorter life span are always are limited in supply. Preparation 
of platelet concentrate, its processing and storage is highly cost effective and needs a good blood banking healthcare system to necessitate transfusion practices. ${ }^{4,5}$ Hence, this study was conducted to know the appropriate use of blood components especially platelets, which is required to ensure the availability of the same for patients in whom it is really indicated.

\section{MATERIALS AND METHODS}

The present Retrospective study was conducted in the blood bank of a Tertiary Care Hospital in Puducherry over the period of 3 years from January 2012 to December 2015 after obtaining approval from the Institutional Ethical Committee. Only dengue seropositive cases who have been platelet transfused were included in the study. Non-dengue patients and dengue patients who are not platelet transfused were not included in this study. Patients clinical data, platelet count and platelet transfusion given to them were analysed. Guidelines of platelet transfusion as suggested by WHO. ${ }^{6}$ (Table 1) was utilised as the criteria to assess the appropriateness of platelet transfusion during the study.

\section{RESULTS}

A total of 121 dengue patients (seropositive for IgM or IgG) who have been platelet transfused were taken for the study. Majority of the Platelet transfused cases were in the age group between 31 to 40 years followed by third and second decade (Table 2). Among all cases of platelet transfusion, female population was found to outnumber male population. Haemorrhagic manifestations, which were seen in dengue patients includes haematemesis, epistaxis and gum bleeding. Among the 121 dengue patients who have been platelet transfused, therapeutic transfusion with bleeding manifestation included $30(24.7 \%)$ and prophylactic therapy without bleeding manifestation constituted 91 (75.2\%). In this study, patients with platelet count $<10,000 / \mathrm{cu}$. Mm, 26 patients have received prophylactic therapy and 11 patients have received a therapeutic transfusion. Between 10,000 and $20,000 / \mathrm{cu}$. mm, 23 patients have received prophylactic therapy whereas 7 patients received a therapeutic transfusion. Patients between 20,000 and 40,000/cu. mm, 29 received prophylactic transfusion and 23 received a therapeutic transfusion. Moreover, patients with 40,000 and above, 3 received prophylactic transfusion and 2 patients were therapeutically transfused (Table 3 ). Considering the guidelines of platelet transfusion, 42 (39\%) patients with platelet count $>20,000 / \mathrm{cu}$. $\mathrm{mm}$ in absence of bleeding or sepsis received inappropriate transfusion.

\begin{tabular}{|c|c|}
\hline $\begin{array}{c}\text { Prophylactic } \\
\text { Transfusion } \\
\text { (In a non-Bleeding } \\
\text { Patient) }\end{array}$ & $\begin{array}{c}\text { Therapeutic } \\
\text { Transfusion } \\
\text { (In a Bleeding Patient) }\end{array}$ \\
\hline $\begin{array}{l}\text { Platelet count less } \\
\text { than } 20,000 / \mathrm{cu} . \mathrm{mm}\end{array}$ & $\begin{array}{l}\text { - Significant active clinical } \\
\text { bleeding with platelet count less } \\
\text { than } 50,000 / \mathrm{cu} . \mathrm{mm} \\
\text { - Proven disseminated } \\
\text { intravascular coagulation } \\
\text { - Prolonged shock }\end{array}$ \\
\hline & $\begin{array}{l}\text { or Platelet Transfusion in Dengue } \\
\text { morrhagic Fever }\end{array}$ \\
\hline
\end{tabular}

\begin{tabular}{|c|c|c|c|}
\hline \multirow{2}{*}{$\begin{array}{c}\text { Age in } \\
\text { Years }\end{array}$} & \multicolumn{3}{|c|}{$\begin{array}{c}\text { No. of Patients Received Platelet } \\
\text { Transfusion }\end{array}$} \\
\cline { 2 - 4 } & Male & Female & Total \\
\hline $0-10$ & 6 & 7 & 13 \\
\hline $11-20$ & 12 & 8 & 20 \\
\hline $21-30$ & 11 & 12 & 23 \\
\hline $31-40$ & 12 & 17 & 29 \\
\hline $41-50$ & 8 & 12 & 20 \\
\hline$>50$ & 9 & 7 & 16 \\
\hline Total & $\mathbf{5 8}$ & $\mathbf{6 3}$ & $\mathbf{1 2 1}$ \\
\hline Table 2: Age and Gender Distribution Among Patients with \\
Platelet Transfusion \\
\hline \multicolumn{4}{|c}{} \\
\hline
\end{tabular}

\begin{tabular}{|c|c|c|}
\hline $\begin{array}{l}\text { Platelet Count } \\
\text { in cu. mm }\end{array}$ & $\begin{array}{l}\text { Therapeutic } \\
\text { Transfusion }\end{array}$ & $\begin{array}{l}\text { Prophylactic } \\
\text { Transfusion }\end{array}$ \\
\hline$<10,000$ & 11 & 26 \\
\hline $\begin{array}{l}10,000 \text { to } \\
20,000\end{array}$ & 7 & 23 \\
\hline $\begin{array}{c}20,000 \text { to } \\
30,000\end{array}$ & 6 & 18 \\
\hline $\begin{array}{c}30,000 \text { to } \\
40,000\end{array}$ & 4 & 21 \\
\hline $\begin{array}{c}40,000 \text { to } \\
50,000\end{array}$ & 1 & 3 \\
\hline$>50,000$ & 1 & 0 \\
\hline Total & 30 & 91 \\
\hline \multicolumn{3}{|c|}{$\begin{array}{c}\text { Table 3: Distribution of Platelet Transfusions in Relation } \\
\text { to Various Platelet Counts }\end{array}$} \\
\hline
\end{tabular}

\section{DISCUSSION}

Dengue is a self-limiting acute mosquito transmitted disease characterised by fever, headache, muscle, joint pains, rash, nausea and vomiting. Some infections result in Dengue Haemorrhagic Fever (DHF) and in its severe form Dengue Shock Syndrome (DSS) can threaten the patient's life primarily through increased vascular permeability and shock. Dengue fever has emerged as a major public health problem in tropical and subtropical regions across the world. With an increase in the global burden of this arboviral infection, healthcare services are continuously striving to improve patient management. ${ }^{7}$ In patients with dengue haemorrhagic fever or dengue shock syndrome, duration of shock is the main risk factor for severe bleeding. Hence, early recognition and prevention of shock is the key to treatment. Serial monitoring of packed red cell volume along with judicious intravenous therapy reduces the use of blood products and shortens hospital stay. ${ }^{7}$

Pathogenesis of thrombocytopenia in dengue infection is not fully understood and it maybe multifactorial. Immunemediated (antigen-antibody mediated) destruction of platelets is considered to be the most important factor. For example, one study found presence of antibodies directed against dengue virus nonstructural protein 1 (NS1) that showed cross-reactivity with human platelets and endothelial cells, which lead to platelet and endothelial cell damage and inflammatory activation. ${ }^{8}$ In most patients, bone marrow responds to peripheral platelet destruction with increased production of platelets. Overtime, immune-mediated destruction of platelets ends and spontaneous recovery in platelet counts is seen in almost all patients. The degree of thrombocytopenia varies in dengue infection and platelet count maybe extremely low in few patients. 
Platelet transfusions have been done in many patients with dengue related thrombocytopenia; however, response to platelet transfusion is not fully studied in these patients.

Our study showed that majority of platelet transfusion occurred in the age group of 30 to 40 years, which was in contrast to the study of Chuansumrit et al where it was noted that the highest percentage of platelet transfusion cases were in the age group of 10-14 years. ${ }^{9}$ Favouring the present study, Ayyub et al and Lye et al noted adult preponderance in age group of 20-40 years. ${ }^{10,11}$ In the present study, out of 121 cases, 30 cases $(24.7 \%)$ had bleeding manifestations. In contrast to our study, Pallavi et al reported that only 21 patients (6.12\%) presented with haemorrhagic manifestations. ${ }^{12}$

In 42 out of total 121 cases, patients though their platelet counts were $20,000 / \mathrm{cu}$. mm and above, having not showed any bleeding manifestations or signs of sepsis, they were transfused with platelets. Thus, the WHO guidelines for platelet transfusion were ignored and exploited committing a significant number of $42(34.7 \%)$ patients to unnecessary hazards of blood transfusion. The percentage of inappropriately transfused platelets in the studies conducted by Pallavi et al and Ahamed et al were found to be $36 \%$ and $56 \%$ respectively. ${ }^{1,12}$ Makroo also stated that many times the indications for prophylactic platelet transfusions were not according the guidelines as prescribed by WHO. Clinicians, because of intense social pressure and the so called dengue panic syndrome, demand for platelet transfusions though it is actually not needed. In our study, 37 (30.5\%) of those who were platelet transfused were in the platelet range of less than 10,000 whereas in Makroo et al study the majority of dengue cases who were platelet transfused was between 20,000 and $40,000.2$

According to Sellahewa, the prophylactic platelet transfusion for dengue are baseless and appear to be an irrational and inappropriate intervention. ${ }^{13}$ Platelet transfusions are hardly ever required even with counts as low as $10,000 / \mathrm{cu}$. mm because the circulating platelets are haematologically active and sufficient to prevent bleeding by thrombocytopenia. ${ }^{14}$

Clinicians should be very well made to know the awareness of platelet transfusion and its more associated risks than its advantages. Repeated indications of platelet transfusion can result in transfusion transmitted infections as well it can cause transfusion related adverse events. In developing countries like India where the prevalence of transfusion transmitted infections like AIDS are especially high, Rapid card tests and ELISA testing are commonly employed, which are actually not highly sensitive when compared to Nuclei acid test. ${ }^{1}$ So, multiple platelet transfusions, irrespective of appropriate indications can put the patient in serious transfusion-induced complications such as febrile non-haemolytic transfusion reactions, bacterial sepsis, transfusion-related acute lung injury, allergic reactions, alloimmunization, and platelet refractoriness, pulmonary oedema and transfusion transmitted infections.7,15 Khan Assir et al also revealed that Platelet transfusion despite increasing platelet count in half the recipients neither stopped the progression to severe bleeding nor shortened the time to cessation of bleeding. This proves that a high baseline platelet count and a successful platelet transfusion cannot prevent progression to severe bleeding. ${ }^{15}$
Blood transfusion services constantly face challenges year after year during dengue outbreaks due to lack of evidencebased guidelines for clinical use of blood and blood components. The demand for platelets and Fresh frozen plasma is increasing due to more number of cases with dengue haemorrhagic fever and dengue shock syndrome. As platelet products are cost effective, precious and time consuming for preparation, there is a need to implement best platelet transfusion practices especially in developing countries like India. Irrational use of platelets will put the patient at a huge risk.

\section{CONCLUSION}

In general, platelet transfusion are given only when there are serious haemorrhagic manifestations. It is not indicated in all causes of thrombocytopenia and may indeed be contraindicated in certain conditions. In addition to lack of knowledge about evidence-based guidelines, social pressure and panic-like situation leads to inappropriate use of precious platelet components during dengue fever outbreaks. A regular transfusion related audit or forming a committee comprising clinicians and transfusion medicine specialists in addition to regular awareness programs in the name of continuing medical education can be the effective way of increasing the likelihood of improving transfusion practices. Also, a better system of management with donor registration, proper guidelines for platelet transfusion and awareness programs will be helpful for better management of dengue fever and its complications.

\section{REFERENCES}

1. Ahamed SI, Bharath RR. Role of platelet transfusion and its misuse in managing dengue fever. Int J Sci Stud 2015;3(3):110-13.

2. Makroo RN, Raina V, Kumar P, et al. Role of platelet transfusion in the management of dengue patients in a tertiary care hospital. Asian J Transfus Sci 2007;1(1): 4-7.

3. Gupta N, Srivastava S, Jain A, et al. Dengue in India. Indian J Med Res 2012;136(3):373-90.

4. Thomas A, Contreras M, Knowles S. Blood component treatment: a retrospective audit in fine major hospitals. J Clin Pathol 1991;44(9):734-39.

5. Verma A, Agarwal P. Platelet utilization in the developing world: strategies to optimize platelet transfusion practices. Transfus Apher Sci 2009;41(2):145-9.

6. Dengue guidelines for diagnosis, treatment, prevention and control, Geneva. World Health Organization 2009.

7. Kaur P, Kaur G. Transfusion support in patients with dengue fever. Int J App Basic Med Res 2014;4(3):8-12.

8. Lin $\mathrm{CF}$, Wan SW, Cheng $\mathrm{HJ}$, et al. Autoimmune pathogenesis in dengue virus infection. Viral Immunol 2006;19(2):127-32.

9. Chuansumrit A, Phimolthares V, Tardtong $\mathrm{P}$, et al. Transfusion requirements in patients with dengue hemorrhagic fever. Southeast Asian J Trop Med Public Health 2000;31(1):10-4.

10. Ayyub M, Khazindar AM, Lubbad EH, et al. Characteristics of dengue in a large public hospital, Jeddah, Saudi Arabia. J Ayub Medical Coll Abbottabad 2006;18(2):9-13. 
11. Lye DC, Lee VJ, Sun Y, et al. Lack of efficacy of prophylactic platelet transfusion for severe thrombocytopenia in adults with acute uncomplicated dengue infection. Clin Infect Dis 2009;48(9):1262-5.

12. Pallavi P, Ganesh CK, Jayashree K, et al. Unfurling the rationale use of platelet transfusion in dengue fever. Indian J Hematol Blood Transfus 2011;27(2):70-4.

13. Sellahewa KH. Management dilemmas in the treatment of dengue fever. Dengue Bull 2008;32:211-8.
14. Kumar ND, Tomar V, Singh B, et al. Platelet transfusion practice during dengue fever epidemics. Indian J Pathol Microbiol 2000;43(1):55-60.

15. Assir KMZ, Kamran U, Ahmad HI, et al. Effectiveness of platelet transfusion in dengue fever: a randomized controlled trial. Transfus Med Hemother 2013;40(5):362-8. 